\title{
Anterior Mediastinal Pseudo-Tumor Tuberculosis: Should We Settle for This Diagnosis?
}

\author{
Ammor FZ ${ }^{* 1}$, Rabiou $\mathrm{S}^{1}$, Issoufou $\mathrm{I}^{1}$, Belliraj $\mathrm{L}^{1}$, Ghalimi $\mathrm{J}^{1}$, Serraj $\mathrm{M}^{2,3}$, Ouadnouni $\mathrm{Y}^{1,3}$ and Smahi $\mathrm{M}^{1,3}$ \\ ${ }^{1}$ Department of Thoracic Surgery, CHU Hassan II Fes, Morocco \\ ${ }^{2}$ Pneumology Department, CHU Hassan II Fes, Morocco \\ ${ }^{3}$ Faculty of medicine and pharmacy, USMBA, Fez, Morocco
}

${ }^{*}$ Corresponding author: Dr Ammor FZ, Department of Thoracic Surgery, CHU Hassan II Fes, Morocco, Tel: +212652090910, E-mail: dr.a.ammor@gmail.com

Citation: Ammor FZ, Rabiou S, Issoufou I, Belliraj L, Ghalimi J, et al. (2016) Anterior Mediastinal PseudoTumor Tuberculosis: Should We Settle for This Diagnosis? J Case Rep Stud 4(2): 211. doi: 10.15744/23489820.4.211

Received Date: January 15, 2016 Accepted Date: April 18, 2016 Published Date: April 20, 2016

\section{Clinical observation}

Mr M.Y., 32 years old, presented since 5 months Dyspnea associated with a productive cough, in a context of night sweats and encrypted weight loss $5 \mathrm{~kg}$ in 3 months and who has consulted in a different formation other than ours.

Physical examination found: polypnea to 25 cycles/min, with a blood pressure at $120 / 80 \mathrm{mmHg}$. The cervico-thoracic examination noted a higher cellar syndrome with swelling in Pilgrim and a turgor of the jugular veins. He has combined to a collateral vein circulation at the cervical level of and high thoracic region.

Face Chest x-ray had highlighted right anterior Mediastinal opacity with right low abundance pleural effusion (Figure 1). On a chest CT scan with contrast injection, the mass was tissue, heterogeneous, and measured $73 \times 93 \times 108 \mathrm{~mm}$. This mass included the superior vena cava and right innominated venous trunk that was the seat of intraluminal thrombosis associated with mediastinal lymph nodes (Figure 2).

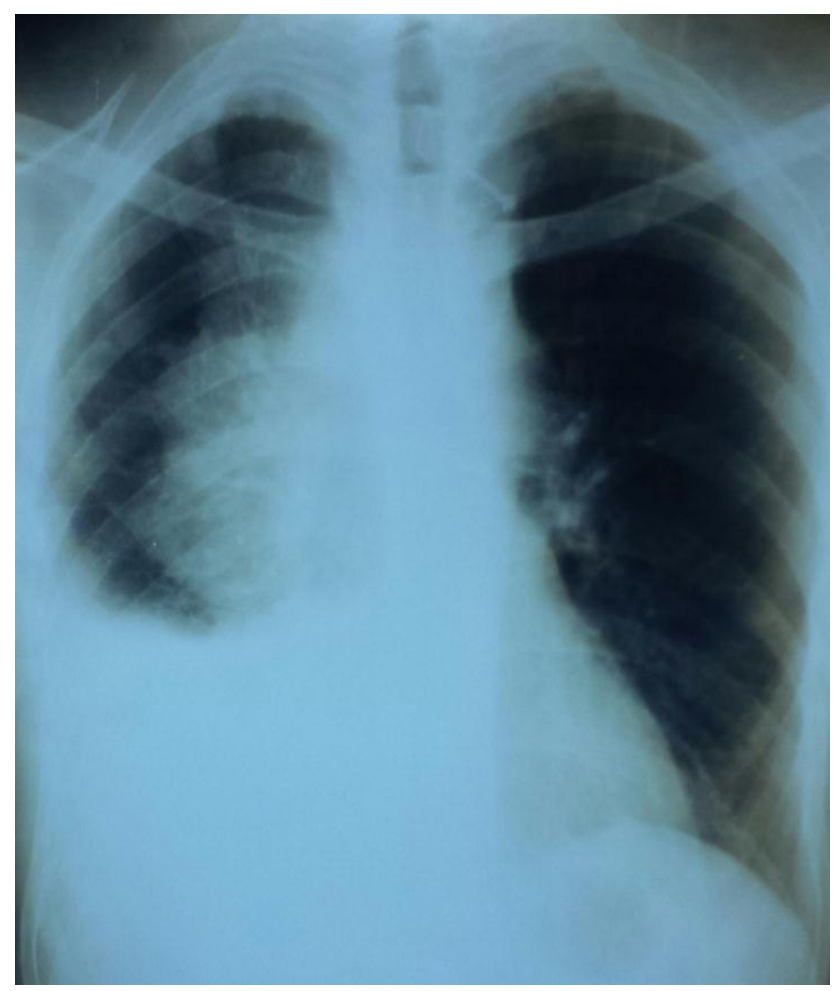

Figure 1: A face Chest $\mathrm{x}$-ray objectifying a lateralized a right Mediastinal opacity, jagged edges, associated with right low abundance pleural effusion 


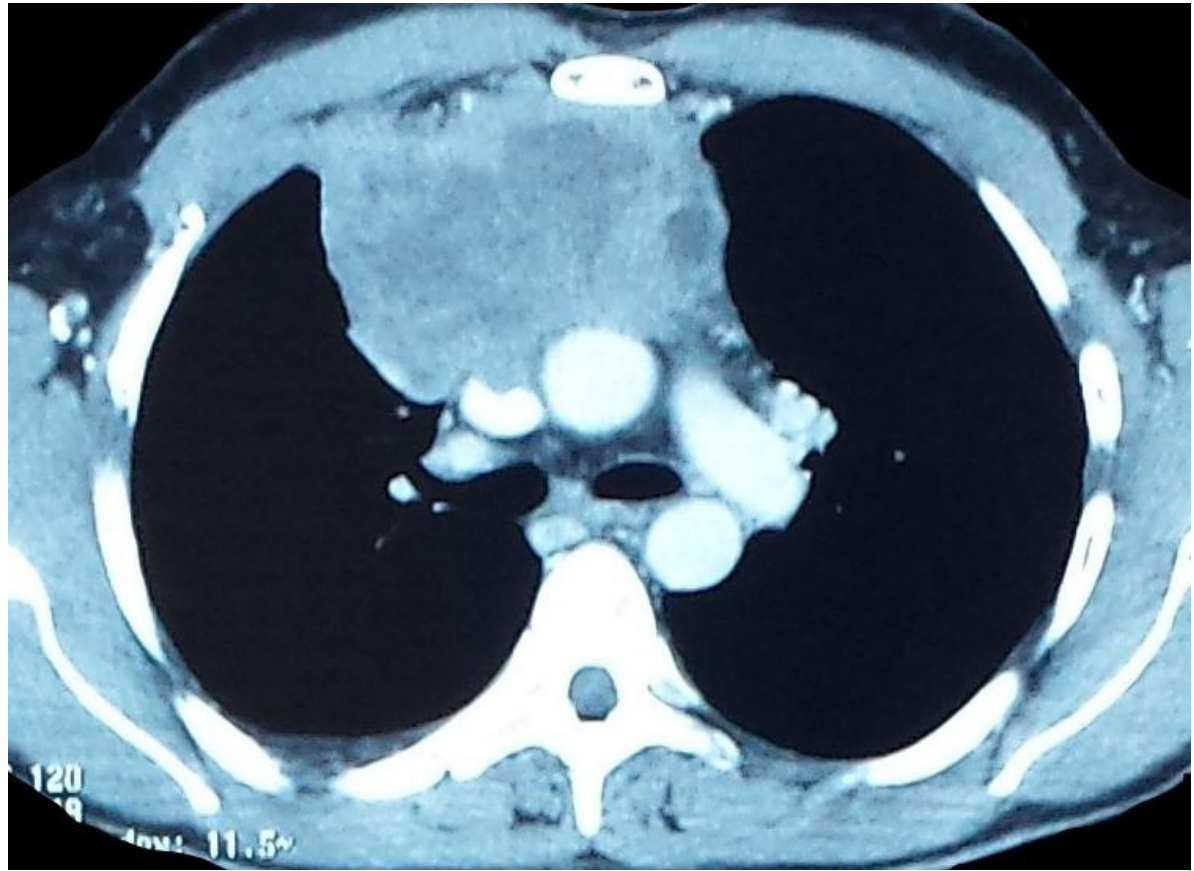

Figure 2: Chest CT scan showing a right antero-posterior mediastinal mass, tissue, heterogeneous, contact with the Mediastinal vascular structures, without obvious wall extension

The histology of a carrot obtained through a biopsy guided by the scanner done in other hospital, confirmed the diagnosis of caseo-follicular tuberculosis with caseous necrosis (Figure 3).

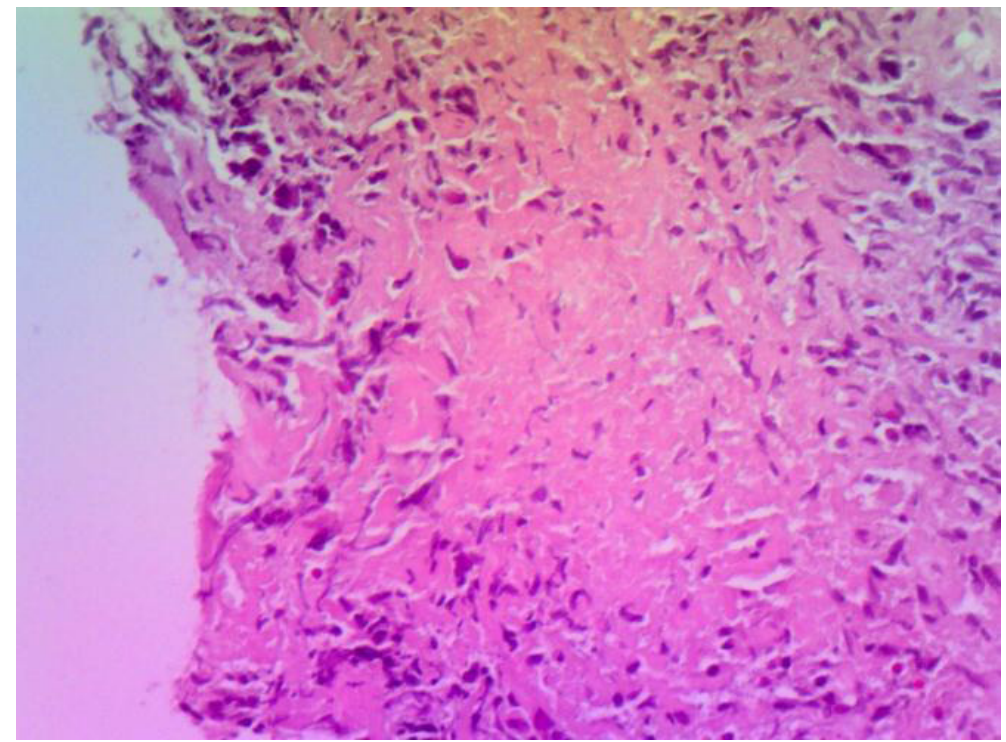

Figure 3: Histological section of epithelioid subependymal giant cell Granuloma centered of caseous necrosis (HEx200)

With this histological result coupled with signs of tuberculosis impregnation present in clinic context, it was decided to establish an anti-tuberculosis chemotherapy.

Note that the patient has not received investigations looking for immuno-deficiency or infringement of TB since other doctors had histologic evidence in order to start the anti-bacillaire treatment.

The evolution 3 months after had been marked by worsening of dyspnea, with a painful swelling of the right chest wall earlier, associated to a right liquid pleural effusion syndrome. This has motivated the patient to consult in our hospital.

So what will be your therapeutic conduct?

\section{Discussion}

Toward this unusual trend, at 3 months of tuberculosis treatment well led, the indication of a chest CT scan is required (Note that the patient has not received MRI due to lack of means). This scanner had indicated a visible and harmonious enlargement of the 
mediatisnal mass volume with parietal extension corresponding to the described swelling (Figure 4). As part of a diagnostic confrontation, a surgical biopsy had been achieved. This later allowed to collect a macro-fragments which histological and immuno-Histochemical analysis returned favor to a high-grade malignant non Hodghkinien lymphoma B-cell CLL according to Internationale Working formulation révisée (REAL) with expression of CD20 (Figure 5A and B).

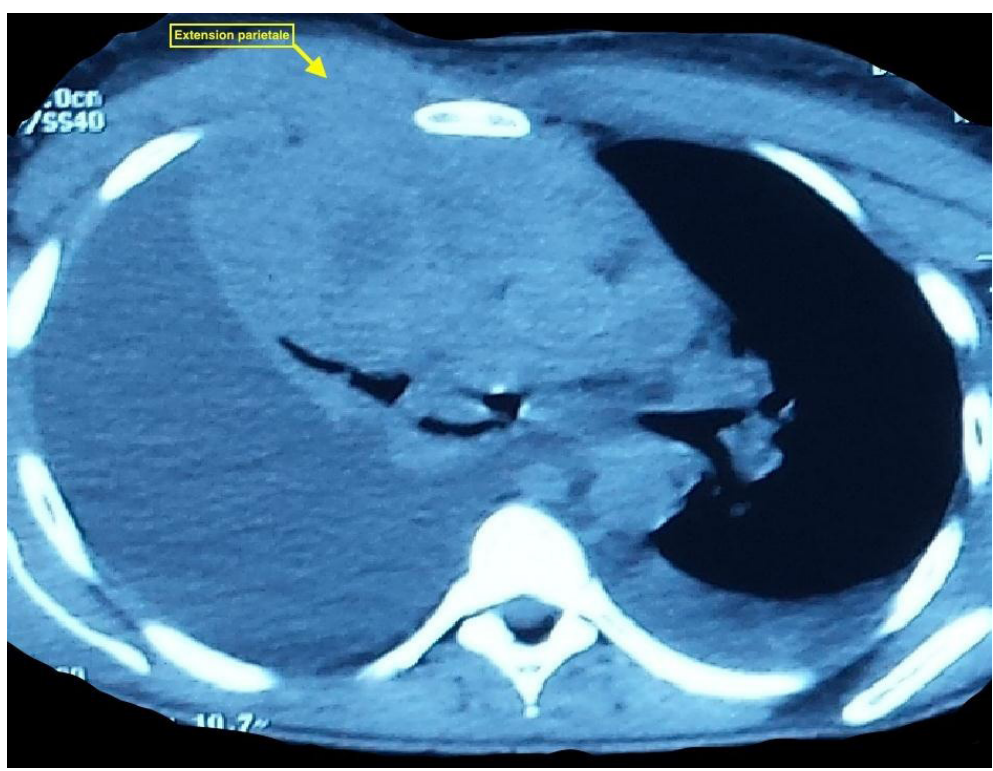

Figure 4: CT chest scan after 3 months of tuberculosis treatment, highlighting the increase in the volume of mass associated with an extension to the anterior chest wall. Note a great abundance pleural effusion

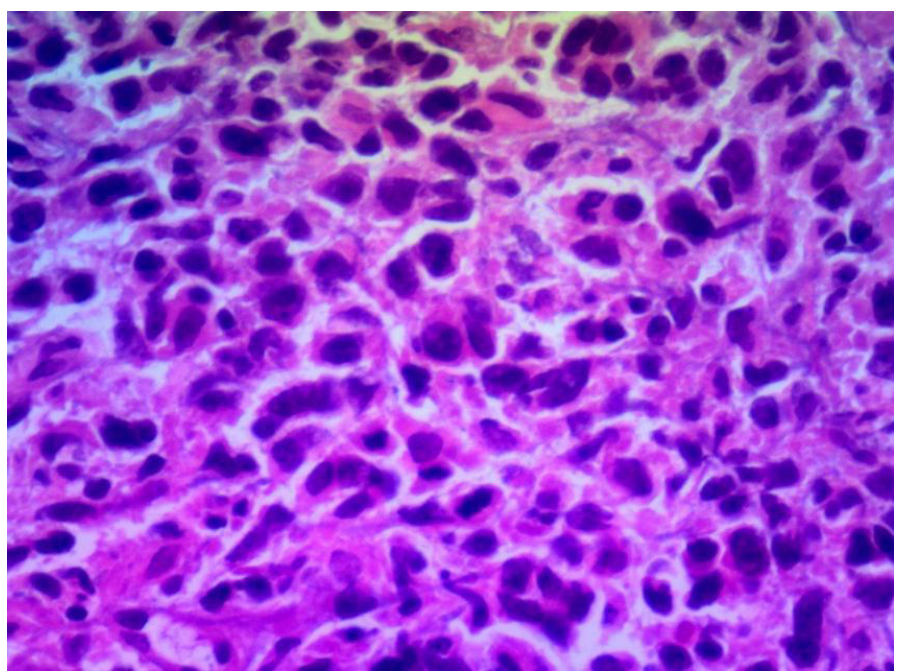

Figure 5A: Histological appearance of high-grade malignant non-Hodgkin Lymphoma (HEx400)

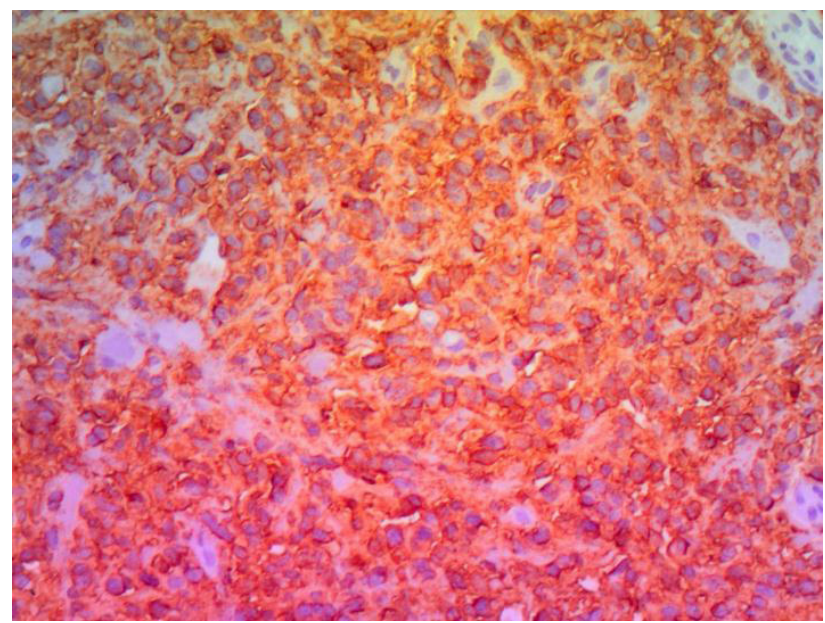

Figure 5B: Histological section of immuno-Histochemistry with expression of CD20 (HEx200) 
Although rare, because it represents only $2.2 \%$ of the study conducted by KUABAN et al. Cameroon [1], tuberculosis and Lymphoma association is a possibility, particularly with a TB endemic notion in Morocco.

Most studies in this area have focused on the concept of wandering diagnostic due to the likelihood of clinico-morphological signs [2]. Histological examination coupled with Immunohistochemistry in the hands of a trained pathologist, allow straightening the diagnosis. Our patient was referred by a further hospital where he has his initial etiologic assessment on which stood an anterior Mediastinal mass with a tumor appearance, but since its association with signs of tuberculosis impregnations, and histological analysis on small samples using a scano-guided biopsy, had likely helped to hide the non-Hodgkin's lymphoma diagnosis. A surgical biopsy by an anterior mediastinotomy could be contributory to diagnose earlier this coexistence. This could avoid a delay diagnosis, which is a prognostic element for this patient.

All this argument highlights this article in order to stress the importance and the place of surgical biopsies of Mediastinal masses earlier by anterior medastinotomy.

The association of Pseudo-tumoral Mediastinal tuberculosis with a hematologic malignancy including malignant lymphoma must therefore be raised against a bad evolution undergoing well conducted tuberculosis chemotherapy. Must know think about it because neither the clinic nor Radiology are specific.

It should be noted to date, there is no protocol codified in the therapeutic strategy of the TB-Lymphoma association. Most of a literature data report a variable delay of 1 to 3 months between the beginning of tuberculosis treatment and the treatment for lymphoma. It is in fact a sporadic clinical case, which some have noted a complete remission after a variable from 1 to 2 years [3]. With a delay diagnosis of 3 months similar to cases reported in the literature, our conduct will consist to continue the tuberculosis treatment on which adds the treatment of lymphoma after a suitable pre therapeutic assessment.

\section{References}

1. Kuaban C, Koulla-SHIRO S, Hagbe P (1997) Features of the dead adult patients with active pulmonary tuberculosis in Yaounde-Cameroon = Characteristic of death of adult tuberculosis patient [Caractéristiques des patients adultes morts de tuberculose pulmonaire active à Yaoundé-Cameroun]. Méd. Af. Noire 44: 345-9.

2. Sorgho lougue-LC, Cisse R, Ouedraogo M, Bamouni YA (2001) A disease can hide another: active pulmonary tuberculosis and Hodgkin lymphoma and Hodgkin = Pulmonary tuberculosis disease [Une maladie peut en cacher une autre : Tuberculose pulmonaire évolutive lymphome hodghkinien]. Médecine d'Afrique Noire 48: 505-8.

3. Hakem D, Ahmad RB, Lafer H, Boudjelida A, Ouadahi N, et al. (2008) Extrapulmonary tuberculosis Association and lymphomas: a buddy not to ignore! [Association tuberculose extrapulmonaire et lymphomes: un binôme à ne pas méconnaitre]. CHU Bab-El-Oued Alger. DOI: 10.1016/j.revmed.2008.10.242.

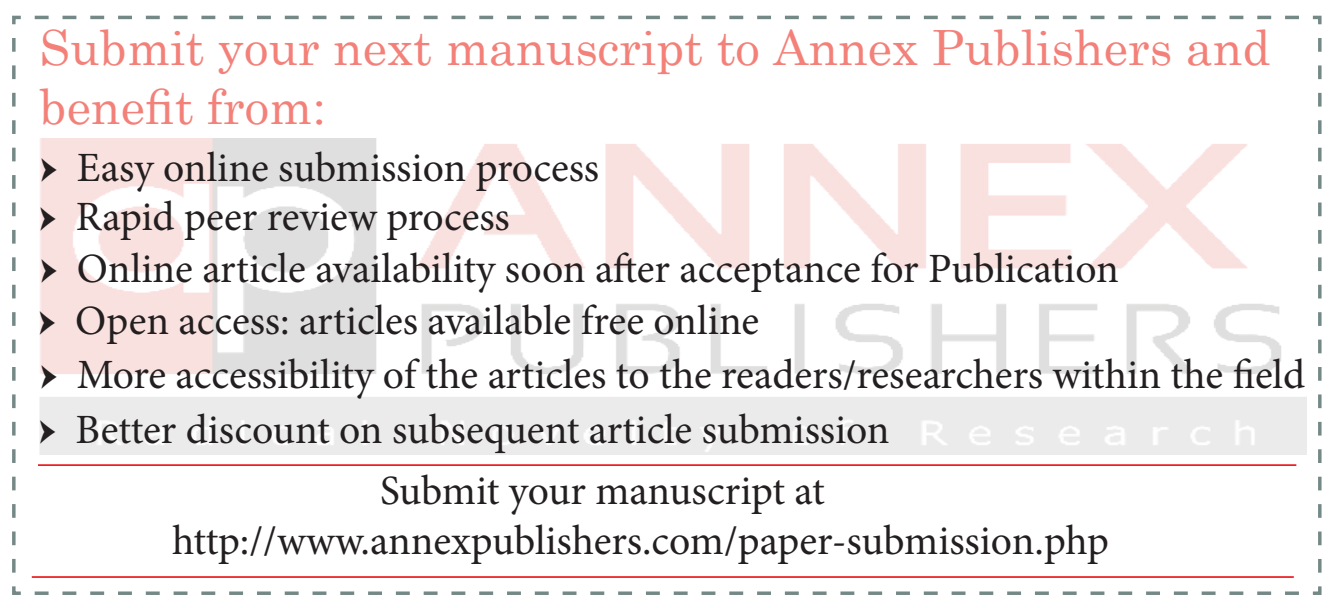

